\title{
LA MELANCOLÍA EN LA OBRA DE PEDRO GATELL, CIRUJANO Y MARINO ILUSTRADO
}

\author{
Jose Luis Peset \\ Instituto de Historia. Centro de Ciencias Humanas y Sociales. CSIC \\ joseluis.peset@cchs.csic.es
}

Recibido: 12 diciembre 2012; Aceptado: 2 junio 2013.

Cómo citar este artículo/Citation: Peset, Jose Luis (2014), "La melancolía en la obra de Pedro Gatell, cirujano y marino ilustrado", Asclepio 66 (1): p033, doi: http://dx.doi.org/10.3989/asclepio.2014.07

RESUMEN: La melancolía es una emoción de moda desde el Renacimiento hasta hoy, también en la llustración la razón se vio acompañada de fuertes sentimientos que anunciaban el Romanticismo. Personaje destacado en este terreno es Pedro Gatell, cirujano naval e infatigable escritor. En sus novelas y textos morales muestra las principales novedades que surgen en la vivencia melancólica y en su comprensión.

PALABRAS CLAVE: Melancolía; España; Siglo XVIII; Emociones.

ABSTRACT: Melancholy is an emotion that has been in fashion from the Renaissance until now. During the Enlightenment, human reason was accompanied by strong feelings preparing for Romanticism. A prominent personality in this field was Pedro Gatell, naval surgeon and untiring writer. Throughout his novels and moral writings he shows the main developments coming from the experience of melancholy and its interpretation.

KEY WORDS: Melancholy; Spain; $18^{\text {th }}$ century; Emotions.

Copyright: (C) 2014 CSIC. Este es un artículo de acceso abierto distribuido bajo los términos de la licencia Creative Commons Attribution-Non Commercial (by-nc) Spain 3.0. 
La figura del cirujano y marino Pedro Gatell (17451792) es notable por su peculiar trayectoria. Nacido en Cataluña y educado en Cádiz, viaja luego a América y a su vuelta por enfermedad y al parecer por poca afición a la cirugía decide retirarse. Intenta conseguir empleo o ayuda para dedicarse a la ciencia y termina como escritor, de prensa y de libros. Es un gacetillero que mezcla novedades científicas con descripciones y críticas sociales. Su periódico El Argonauta español es un buen ejemplo de la prensa ilustrada y un buen testimonio costumbrista de la vida en Cádiz o Madrid. También fue un ilustrado buen lector de Cervantes, cuya obra cumbre prolonga en una vida del escudero Sancho Panza. También toma el Quijote como un texto ético, que amplía con una obra moralizante inspirada en el caballero y otra en el sirviente. No es extraño este interés por el personaje cervantino en los marinos, desde Malaspina hasta Martín Fernández de Navarrete lo frecuentan. Algún otro texto breve tiene interés entre los escritos del catalán, como unos comentarios sobre el futuro impacto de la independencia de las colonias inglesas en las españolas. Señala con antelación e inteligencia la llegada al sur del joven vecino del norte. (Gatell, 1912).

\section{UN CIRUJANO Y UN SIRVIENTE ENTRISTECIDOS}

Siendo la melancólica una emoción de moda en la Ilustración, no podía faltar en sus muchas páginas. Al fin y al cabo es un militar triste como fue Cadalso, personaje prerromántico, quien prefiriendo Heráclito a Demócrito, con ambos encabeza Los eruditos a la violeta (Cadalso, s.d.). Sin duda, la biografía de Gatell está marcada por las desventuras y las tristezas, sus fracasos como cirujano, como científico y técnico. Proyectó obras en La Habana, quiso dedicarse a la observación y la enseñanza astronómicas. Pero los ecos de la revolución francesa terminaron con lo que parecía asentada generosidad del poder hacia la cultura, también con sus propias convicciones ilustradas. Así el cirujano, sin abandonar su fe en la educación y la ciencia, se muestra retrógrado en filosofía y moral. Sobre todo, le preocupó el posible cambio social, al que se opuso terminantemente. Lo expresó bien en muchísimas páginas, escritas con rapidez y tosquedad, a veces con acierto estilístico, siempre repletas de citas clásicas españolas y grecolatinas. Publicó mucho de forma tardía, pero sin duda encontró apoyo editorial, incluso en la Imprenta Real. Elisabel Larriba lo ha estudiado y editado con inteligencia y esmero (Larriba, 2003a; Larriba, 2005). Otros marinos prolongaron las difíciles experiencias del fin de siglo, héroes siempre en dificultades como Mendoza, Ciscar o Malaspina. Este sabía bien que se encontraba en un vórtice que lo arrastraba con el difícil cambio de siglo (Peset, 1988).

Dejando aparte su propia biografía, varios son los caminos a la melancolía para Gatell, desde luego de forma primordial la lectura del Quijote y la escritura sobre él. La aceptación, como Cervantes impuso, de su obra cumbre como un libro para diversión de melancólicos, se muestra en las figuras que Gatell recrea del hidalgo de la Triste Figura y del deprimido escudero, mayor novedad (Pérez García, 2006). Por otro lado, sus lecturas de una literatura que él considera mala e impía, pero que triunfa en la época, es otro camino hacia la tristeza. Su formación médica y los abundantes escritos de su tiempo sobre los sufrimientos del alma son otro ancho cauce. Mientras los médicos inician los estudios del alma, los escritores anuncian el Romanticismo. También las nuevas costumbres, afrancesadas, alejadas según nos dice del vigor de la tradición propia, afectan al cirujano, que no acepta novedades. Siempre está detrás el miedo a Francia, en donde se ha producido un cambio político fundamental y donde ateísmo y republicanismo estaban a la orden del día. Si Hervás y Panduro se resistía a la mesa francesa (Hervás y Panduro, 1807, v. I, pp. 16-17), en Gatell son perseguidos trajes, bailes y costumbres de allá venidos. A la postre, la caída de la cabeza del Borbón aterrorizará a la corona española, así como a muchos ilustrados. Pero sin duda, hay que repetir que la lectura es un camino real hacia la melancolía, el camino que ya está presente en los Problemata aristotélicos, en Marsilio Ficino o en Huarte de San Juan (Peset, 1999). No podía faltar el tema del literato arrepentido y apesadumbrado -como el militar Cadalso- en que Gatell mismo se inserta, ángel caído por su antigua y culpable pasión por los filósofos modernos.

En sus páginas, la brevedad y la incertidumbre de la vida son temas repetidos, en espera de una buena muerte. Para esta no sirven otras ciencias, ni las opiniones del mundo, todavía menos la moderna «filosofia pestilente» que desprecia a la religión, las leyes y los monarcas. Son nuevos titanes estos autores, con depravada corrupción, peores que los antediluvianos, hay que esperar otro diluvio universal. Estamos, nos dice, en una nueva y peligrosa guerra:

Nos presta las armas esta filosofía decantada, que sin mas instrumentos bélicos que la mentira, la falsedad, la suposición, ha sabido sacar del centro de la bondad a tanta multitud de hombres. Somos Quixotes, ¿pero qué Quixotes? Quixotes que jamás serán Alonsos buenos.

Así pide, además del diluvio, un rayo divino sobre el pueblo español, para que no se corrompa, que como sus antepasados venere la religión, los reyes y las costumbres. Volverá así a los triunfos de antaño.

Él desea buscar la soledad, tal como muestra en algún soneto que aporta, no quiere palacios ni tiranos, como demostrará su criatura el alcalde Sancho ante los duques. Le alcanzaron en tiempos las «obras filosóficas», "bellas producciones», que son sin embargo «venenosa peste», pues «era veneno lo que bebía en 
copas doradas.» Teme esa pretendida "elegancia» y "libertad de conciencia», sin premio para el justo y con premio al injusto. Así, «las causas, el objeto, las miras de los Filósofos modernos», "los libros Quixotescos del día», aunque ponen "las razones, los fundamentos», son el parto de un ratón, orgullo, vanidad, pues «todas las miras de la filosofía moderna, no se dirigen mas que a la perdición de la especie humana. Aprended de mi desengaño, ved que sin embargo mi corazón está lleno de amargura y de pesar solo con la memoria de que también he sido desdichado. Ya dixe que en castigo no he merecido llenar mis deseos, que son la soledad, el verme distante de oír y de ver, y acabar mis días con tranquilidad.» (Gatell, 1792-1793, t. II, pp. 294-300). Cierra La moral de don Quijote con melancolía y culpa, hastiado de la filosofía moderna, buscando la soledad del misántropo. Pero iracundo pide rayos, habla de guerras que restauren el orden que cree perdido. Rayos y guerras que vendrán, pero él no llegará a conocer. El tan solo escribirá insistentemente desde el dolor.

Una muy rica y primera presentación literaria de la tristeza en la España del siglo XVIII es sin duda la autobiografía de Diego de Torres Villarroel. En la profunda melancolía del profesor salmantino se barajan de forma magistral humores, pasiones, pecados y culpas, junto a tratamientos, diversiones y confesiones. Conoce bien la medicina de su época, como el mismo Gatell. También ambos son personajes aislados. Torres se siente incomprendido en su universidad, tanto por ser un estudioso de las ciencias, materias despreciadas en las aulas, como por no ser reconocido como escritor. Pedro Gatell tendrá la misma sensación en la marina y en el mundo de las ciencias, tan precario entonces como ahora, y no menos en el de las letras. Ambos buscarán la distracción de sus negros pensamientos, si bien con diverso resultado. Torres nos cuenta que se encuentra envuelto en vapores, o humazos, haciendo tal vez un juego con el tabaco y el galenismo (Alsinet, 1794; Gusdorf, 1976, pp. 209-215). Recurre como solución a sus diversiones de siempre, amigos y toros, coches y paseos. Va a Madrid, lejana de su tediosa Salamanca (Peset, 1999, pp. 65-83).

Gatell parece responder a Torres, cuando a la vuelta de un fantasioso viaje a la luna, que inserta en $E I$ Argonauta español, se siente afectado por un íntimo pesar. Es asaltado él también por cruel melancolía y marcha a Madrid, visitando como Torres con un amigo el paseo del Prado, Sol y la Plaza Mayor. Este lo amenaza con llevarlo a Zaragoza, sin duda al Hospital de Gracia, como a don Quijote condujo Avellaneda al del Nuncio en Toledo. Era el aragonés un importante hospital para dementes, como muestran bien los elogios de Philippe Pinel, si bien hay que matizar la excelencia de este hospicio (Fernández Doctor, 1987; Diéguez, 2001). Pero en la capital, como nada lo di- vierte ni quita la pena, ni diversiones ni amenazas, su amigo lo lleva a casa de gente de broza en barrio de gente del bronce, es decir libre y ociosa, resuelta y pendenciera, a escuchar la guitarra y la pandereta, para asistir a un baile de candil, unas seguidillas boleras. Así, con esto, se podría quitar la hipocondría. Este rico vocabulario se enlaza con costumbres populares, así el sombrero de tres picos, sin embargo mostrando un desprecio hacia esas formas y diversiones. La posible contaminación de gustos entre clases sociales, asusta al timorato cirujano.

Advierte que al fin gritan bien parado, bien parado; se ríe el paciente de tal expresión, que considera lengua siria:

A esto agarró de nuevo la risa, pero con tal fuerza, que les fue preciso desocupar el puesto antes que se levantase un temporal de los que suelen acontecer en semejantes parajes, porque a un decir Jesús levanta un Manolo la mano, da un manotón al candil, allá van los truenos y lluvia de garrotazos.

Él pregunta de dónde han salido, supone que se bailará así solo por gentes de esta catadura, de «gentalla», con origen en un medio ínfimo. Pero no, no es así. Las niñas pronto aprenden el bolero con el bien parado y el toque de las castañuelas. "No es en el día marcial la que no las sabe cantar y bailar, sin separar las de más fuste.» (Larriba, 2003a, 121-125 y 206). Se para con el último estribillo. En la comedia repiten dos o tres veces y con «palmeteo». A lo bolero se lleva el peinado, con cintas como el toro o la mula, con bandas y flecos (también los hombres), además flores y cabello cubriendo la cabeza, tan ridícula según Gatell como la mondada de los moros. Son las seguidillas mejor consideradas que un aria de célebres cantantes líricas, comenta con sorna. Se lamenta de tantos cascos vacíos, que compara con don Quijote y sus molinos de viento (Gallego, 1988; Lolo, 2003).

Estas aficiones son locuras, no presentes en la historia de España, nos dice arremetiendo a la vez contra las comedias de figurón. Eran elementos frecuentes, esas piezas teatrales y musicales. Buen ejemplo es un manuscrito de la Biblioteca Menéndez Pelayo de Santander, que contiene las representaciones que en el día de Carnestolendas de 1785 tuvieron lugar en el teatro de la casa del duque de Híjar. Así las canciones y el fin de fiesta escrito por su abogado Miguel García Asensio con el título «El Lacayo Marques». Un ridículo figurón se presenta en escena, junto a estos gustos populares. No dejan de aparecer ridículas tonadillas, seguidillas, además de canciones pastoriles interpretadas por elegantes jóvenes (García Asensio, 1785, pp. 70r-123v; Artigas y Sánchez Reyes, 1957, t. I, p. 371). Estos gustos, sin duda, se han impuesto. Si alguien se burla de estas modas, saldrá castigado como Sancho Panza de la venta. Aunque sea sabio será juzgado loco 
como el filósofo Demócrito, nos dice Gatell. Es preciso retornar a las recias tradiciones como las de España, semejantes a las de Roma y Esparta.

Este texto es una buena muestra de las larguísimas -y casi siempre farragosas- críticas de las modas a las que acostumbra este autor, muchas veces aderezadas de franca misoginia. Sus ataques constantes a las vestimentas muestran su encono con Francia, su preocupación ilustrada por el lujo, también su miedo al cambio social. Cada uno debe vestir como conviene a su condición. También comportarse o casarse. No estaba solo, si Hervás y Panduro critica la influencia de los gustos culinarios franceses, en el anónimo Discurso sobre el luxô de las señoras de 1788 se quiere un traje unificado y anticuado, respetando las modas nacionales y tradicionales, que son baratas y honestas, acordes con nuestras tradiciones y creencias, evitando lujo y corrupción de costumbres (la inmoralidad, el boato y la frivolidad). Son más hermosas y evitarán la ruina en la vejez y con ella la enfermedad. Sin duda, el miedo a los cambios en las costumbres femeninas, lleva a un intento de sometimiento de la mujer por la moral, la política y la economía. Incluso se quieren inspirar sus vestidos en la moda militar (Discurso, 2005; Hoffmann, 1995; Bolufer, 1998).

Si este texto comentado se trata de un artículo de prensa, más vuelo quieren tener los que incluye en su prolongación de la vida de Sancho Panza. Si Cervantes quita de en medio a Alonso Quijano, deja en pie a casi todos los personajes de su novela. Y, desde luego, a Sancho, por lo que no es extraño que muchos quisieran prolongar su vida (Flores, 1982). Sin duda, su descripción de la melancolía del criado en el libro en que Gatell quería dilatar su existencia hasta la muerte, alcanza interés si no literario, al menos psicológico. No olvidando ni la moral ni la utilidad, la nueva sensibilidad burguesa, consigue un retrato psicológico del dolor del personaje, motivado por la culpa, la ausencia y la nueva educación.

\section{RAZÓN, EMOCIÓN Y TRABAJO}

Tras la muerte de Alonso es el escudero el personaje más afectado, a quien siguiendo las chanzas de Cervantes, también Gatell relaciona con la herencia. Atiende Sancho como buen hombre su casa y a las mujeres, llorando o conteniendo las lágrimas por imposición del cura. Se describen los lamentos del criado -que contrapone a los sirvientes de su épocamotivados por el agradecimiento al bienhechor caballero, al que considera amo y señor, maestro, amigo e incluso padre. Desaseado y con mal aspecto acompaña a Alonso a la sepultura, permaneciendo hasta que es de allí arrancado por el sacristán, Teresa y su hija. El aprendiz de melancólico parece cercano al suicidio. En casa llora sin consuelo, deja de comer y pierde el sueño. "Todo era dar vueltas de un lado y otro, gemir y suspirar». La vida es imposible, debió acompañarlo en la muerte. Era un amo que lo reprendía con dulzura, pero era él quien decidía sobre los dineros, los caminos e incluso en la palabra:

La confianza que de mí hacía no cabe en comparación. Yo era el depositario de su caudal, yo le distribuía a mi gusto, en fin era yo más dueño de sus cosas que su merced. Era tanta su benignidad y docilidad, que le llevaba por donde quería, y le merecía tan buena opinión, que en todo me daba crédito. Hasta sufría que le respondiese. ¡Ay Dios! ¿puede decirse más de su bondad?

Hay un aprendizaje de la melancolía y un cambio de modelos de virtud, de modelos de héroe virtuoso. A los bellatores siguen los oratores y en fin los laboratores. Primero fue ejemplo el caballero cervantino, pero en Gatell viene luego el clérigo y, por último, el escudero. No come, enflaquece y pierde el color, va en pos de su señor por tanto. Teresa suplica, como los vecinos, pero todo es inútil. «Ya temía llegase a perder el juicio, no perdiese la vida».

La tristeza del clérigo, el llanto por un justo, se debe al remordimiento por haberlo retornado por la fuerza en jaula a casa y a la ausencia de las «conversaciones que tantas veces divirtieron sus melancolías» (Gatell, 1794 , t. I, pp. 9-16 y 22). Llamado por Teresa reconviene al escudero, añadiendo reflexiones y consejos. Fracasa y se retira, invadiendo la tristeza a los personajes y a la aldea. Piensa entonces el clérigo que ha usado palabras "por lo bajo», pero estando el escudero acostumbrado al caballero, debe volver a «hablarle por el estilo de Alonso» (Gutiérrez Cuadrado, 2005). Regaña al criado, pide su resignación y conformidad, para evitar hacerse homicida de sí mismo. Teniendo en cuenta el recuerdo del caballero que se dejó morir de melancolía, le pide como si se tratara de un médico: «divertid en otras cosas la imaginación». Enferma esta facultad del alma, es bueno reconducir sus pensamientos, recomendaban los médicos y por supuesto Gatell. El cura ordena darle vino y así toma algo de sopa. Le exige escuchar a dios, atender a la familia y a los amigos y recordar al caballero, maestro de paciencia, sufrimiento y conocimientos. Pide equilibrada actitud, estar sereno, no quejarse, paciencia, sufrimiento e insensibilidad. No sentir es torpeza pero también sabiduría, estoicismo y cristianismo. Reflexión y entendimiento llevan a una vida justa, estoica, católica.

También reacciona el buen Sancho al amor familiar, ante las recriminaciones de esposa e hija. Sobre todo ante el amor de la pareja, ese sanador matrimonio:

un amor sencillo, casto y honesto; no el amor que reina en la época presente, amor interesado y nada puro el más, amor aparente, que dura solo, que solo se manifiesta en el exterior y cuyas demostraciones son solo hijas del porque no digan. iTriste época la 
presente! (Gatell, 1794, t. I, pp. 23-28, 35-36, 74-75 y 94; Staël, 2007).

Teresa escucha a Sancho llamar en sueños al caballero, intentando con su famosa propuesta de una nueva vida bucólica arrebatarlo de brazos de la muerte. Son así recordadas las críticas cervantinas al bucolismo literario, que se superponen a las dirigidas a los libros de caballería. Es un tema que le interesará sobremanera, así en otra amplia cita en La moral del mas famoso escudero Sancho Panza, vuelve sobre la tristeza de la muerte del caballero, a las frases con que lo llama el sirviente a la vida campestre para evitar la mortal melancolía (Gatell, 2010, pp. 241-244). Ese sueño lo hace feliz, riendo alegre en esas sendas arcádicas.

La razón se debe oponer a la locura, el cariño a la tristeza. Pero ante el recuerdo del amo, incluso de sus estoicos consejos, de nuevo recae. Así teme el cura que vaya a perder la cabeza. Cambia este entonces la estrategia, pues no han valido ni principios ni ejemplos. Ahora combina razón y autoridad, usa del arte de persuadir. El alma de Sancho no es tan ingenua ni tan torpe y ha aprendido mucho junto al señor. Ya no es ese ser semejante a su amado pollino que era Sancho:

Señor, las tristezas no se hicieron para las bestias, sino para los hombres; pero si los hombres las sienten demasiado, se vuelven bestias (Quijote, II, c. 11).

Comenta esta frase Sancho en La moral del mas famoso escudero Sancho Panza. Es preciso intentar salir de la tristeza, sabiendo el peligro de devenir bestias, o locos furiosos, o bien morir. El consuelo está en las reflexiones y en las consideraciones cristianas (Gatell, 2010, pp. 131-136). El barbero entonces propone que vaya a trabajar al campo, a cuidar la hacienda, una inmejorable diversión de los pesares. Gran pesar, que vencerá por el trabajo y la evitación del ocio. La esposa parece estar de acuerdo, mejor hubiera sido no conocer a Alonso, quedar cuidando cabras o labrando.

Sin duda, el trabajo será muy apreciado en la época -ya lo era para los arbitristas y reformadores desde el Renacimiento- y así lo muestran ahora las reformas ilustradas. La persecución de vagos y maleantes, la dignificación del trabajo o la labor de las Sociedades Económicas lo evidencian. Asimismo hay disposiciones valorando la producción textil de las mujeres y procurando su enseñanza, lo que se propuso el imaginario alcalde Sancho de Gatell. También los médicos, como el francés Pinel, consideran favorable para la curación de los enfermos mentales el trabajo, tal como según él se practicaba en el hospital de Zaragoza. Los recuerdos de Altisidora sobre la labor manual, también fueron conocidos a un buen lector de Cervantes. Décadas antes Cristóbal Méndez, un médico de Lepe, que estudió en Salamanca y trabajó en México, publicó en Jaén en 1553 un Libro del ejercicio corporal. Sus primeras citas son para Aristóteles y, desde luego, Galeno, cuyas sex res non naturales sin duda tendría en cuenta.

Reconoce el autor que habla para las mujeres ociosas, que caen en enfermedades por esta causa. Por el ocio tienen menos hijos, aseguraba. Se remonta a Ptolomeo para afirmar que en España las mujeres trabajaban en el hogar, con sus hijos y en el campo. Trabajo es considerado el vigilar y corregir los fallos de las sirvientas, incluso si son provocados. Recomienda a las mujeres limpiar y suavizar el lino -tareas precisas para su preparación-, hilar y devanar madejas, trabajarlas, coser, tejer cintas y hacer trenzas. Y ahora también tejidos ricos de oro, gorgueras, tocados o franjas. En 1530 mandó la emperatriz -nos dice- provisión a México para que las mujeres hicieran algún ejercicio, ofreciendo lino. Ofendidas las señoras, el obispo las convenció del alto honor que se las dispensaba. Recomienda para ellas el médico los paseos por casa; a las monjas además de estos, el coro y sus trabajos que no les faltan (Méndez, 1991, pp. 231-235; Ruiz Somavilla, 1993). Gatell encomienda a su personaje Sancho, en el relato de su vida, como alcalde de aldea, arcadia ilustrada, la enseñanza del hilado a las mujeres.

En la llustración renacen estos temas, así en otro escritor de prensa, como es Nipho. Se queja de la España de su tiempo, por los abusos que ve como cortejos y lujos, considera a la nación como inconstante francesa, engañosa italiana y lasciva inglesa. Amancebada con la riqueza y la sensualidad, que son extranjeros males que la llevan a su declive. Se echa de menos los antiguos tiempos en que la propia reina Isabel acudía a los conventos con una canastilla, pues las camisas de Fernando procedían de sus manos. Las activas órdenes renacentistas, las de Ignacio de Loyola o Teresa de Cepeda y Ahumada están a las puertas.

Con este prodigioso exemplo puso estacada a los abusos y todas las Monjas aun las mal contentas, por tener parte en la imitación de tan santa y discreta Reyna, trabajaban a porfía, de modo que insensiblemente la tarea las redimió de muchíssimas locuras, que se creyeron incurables, aun con haver aplicado antes remedios más fuertes (Nipho, 1755, pp. 5-18, cita en 17; Enciso, 1956).

En aquella época se dudaba de los lujos, se estimaba el trabajo, por lo que Altisidora podía hacer bolillos y encajes y Sancho cuidar tierras y ganados. El arte ha reproducido a muchas reinas, santas y monjas -luego burguesas y proletarias- trabajando. Hasta la reina Victoria ha sido representada con una rueca. También san Julián el patrón de la ciudad de Cuenca, que fue famosa y rica por sus textiles, se relaciona con tareas de esta naturaleza para el socorro de pobres.

\section{SUEÑOS, LABRANZA Y NARRACIÓN}

El sueño es un tema clásico y moderno en la llustración, Luciano de Samosata y Diderot son buenos ejem- 
plos de lo uno y lo otro. En la literatura castellana, Quevedo o Torres son modelos a imitar. Cadalso inaugura con un sueño su Óptica del cortejo (M. A. Ramírez y Góngora en obra falsamente atribuida a Cadalso, 1790). Y, en la época, es difundido Shakespeare. Así es empleado por Pedro Gatell el soñar, como señaló E. Larriba, para la crítica de la medicina, sin duda en la senda del matemático salmantino. Arremete contra el cervantino graduado por Osuna, quien lo mataba de hambre en Barataria, siempre deseoso de evitar en su ínsula la presencia de médicos malos, ignorantes, imprudentes e indiscretos. También contra los médicos que no saben ni a sí mismos curarse. No duda en discutir como ilustrado la peligrosa y tradicional medicina galénica, queriendo sencillez, prudencia, observación y práctica, defensa hipocrática de la naturaleza. No parece creer en muchos medicamentos, siguiendo las ideas de la época, pues critica a quienes abusan en busca de la inmortalidad. En El Argonauta una voz sobrenatural le encomienda la salvación de la medicina, quemando libros como en una nueva inquisición cervantina, salvando tan solo a Hipócrates y van Swieten, entre los españoles a Solano de Luque (Gatell, 1794, t. 1, pp. 168-170; Larriba, 2003a, pp. 147-152 y 203-206; Larriba, 2005, pp. 115-123.)

Se pregunta Sancho por qué no soñaba don Quijote, $\tan$ lleno de ilusiones; responde el beneficiado que por la fortaleza del cerebro bien constituido (ni débil ni enfermo), o porque no tenía hambre, pues ocurre al no cenar. Los médicos, desde luego, se ocupan también de los trastornos del sueño (Cullen, 1788-1791, t. III, pp. 386-387). Pero sin duda este pertenece a Sancho, si bien el caballero soñó en la cueva de Montesinos. Incluso el cura cervantino considera los libros de caballería «ficción, fábula y mentira, y sueños contados por hombres despiertos, o por mejor decir, medio dormidos» (Quijote, II, c. 1). Pero Sancho en las páginas cervantinas hará un maravilloso paralelismo con la muerte, que entristece, iguala o bien consuela y premia. Herencia de la palabra del caballero y de la iglesia, se enriquece el simbolismo onírico, significando curación y felicidad, o bien tristeza y muerte. Se puede recordar que en el mundo clásico, la misma familia divina reúne sueño y muerte. Si el Romanticismo renovará este interés (Montiel, González de Pablo, 2003; Montiel, 2008), antes Luis Antonio Muratori el ilustrado bibliotecario de Módena, considera el sueño resultado de la fantasía. Puede venir de malas digestiones, fiebres o por problemas en los humores, así la sangre, o bien la melancolía. Les reconoce efectos sanadores, a veces se encuentran en ellos remedios contra la enfermedad. Pueden informar-además de sobre aspectos exteriores- sobre nuestro cuerpo y nuestra alma y nuestras melancolías. Si bien no son revelaciones, no se trata del diablo. A veces alteran las imágenes de la mente, causan terror, pero otras la fantasía forma comedias ordenadas y graciosas (Muratori, 1777, p. 125; Cardano, 1999; Egido, 1994).
Va mejorando el juicio del criado en las páginas de Gatell, pero se acuerda de su señor, a la vez que el dinero mengua. Riñe con el bachiller, a pesar de mediar el clérigo, asegurando que «murió Alonso de melancolía de haberse visto vencido». La derrota, una derrota última sería el motivo de la tristeza y la muerte, ya que:

lo mató por la melancolía que le ocasionó: que no es menester espada, trabuco ni puñal para matar a uno, que una palabra sola basta para echar al otro mundo mil hombres de honor. Esto bastantes veces

lo dijo mi difunto amo.

El bachiller lo admite, es acusado por la gente, el cura también lamentaba siempre su propio papel en traerlo de Sierra Morena. Teresa pide calma y reconciliación, pero es apedreado el culpable por unos chicos, encerrándose en casa con "fúnebres meditaciones», rendido «en cama sin consuelo» (Gatell, 1794, t. 1, pp. 41, 48, 53, 66-69, 75-76 y 81; Pi y Molist, 1886). Ante los rumores y críticas del pueblo, temiendo el castigo huye el bachiller.

El clérigo aprovecha la mala conciencia de Sancho -religioso por sentimiento y corazón-y así, tras confesarse, vuelve al trabajo de campo. Pero ante la dureza de la labor, pronto echa de menos las dulzuras de la vida caballeresca, las casas de los duques y don Antonio, las bodas de Camacho, el cargo de gobernador y sus esperanzas en más altos destinos. Siempre Gatell teme el abandono del campo por la ciudad y sobre todo la corte. «iOjala que nunca hubiera dejado una vida que ahora me es tan pesada!». La soledad aumenta la tristeza, recordando la pasada felicidad, "y así Sancho se veía molestado de las reflexiones, que aumentaban su melancolía» (Gatell, 1794, t. 1, pp. 92-94 y 136). Teresa trabaja en el hilado y la cocina, cuidándolo, el clérigo emplea la persuasión y la oratoria -profana o sagrada- y la palabra amiga. Cuando encuentra compañía y charla se anima, así preguntado por don Quijote se convierte en narrador. Nos recuerda las lecturas en las ventas, la literatura de transmisión oral, los contadores de cuentos, los relatos de bandidos como Francisco Esteban, famoso bandolero andaluz. Señalemos a ese nuevo Sancho narrador, nada extraño en las tradiciones orales antiguas, en Cervantes aparecen con frecuencia esas lecturas o narraciones. Contrapone así las comedias de la ciudad con los relatos del campo.

El cura y los otros amigos comparan con el original impreso y admiran la veracidad de Sancho. No es solución sin embargo, la memoria de la desgracia empeora al criado, quien llora y teme enloquecer como el señor. Elogia la vida del escudero y la militar; mientras, Teresa prefiere el trabajo y el hogar, la familia sin duda (Gatell, 1794, t. 1, pp. 98-114). Gatell afirma la importancia de los viajes para el conocimiento, él puede presumir de los suyos por América y España, incluso a la luna como Cyrano de Bergerac. También 
el escudero con Gatell se hace poeta. Recordemos la afirmación del Sancho cervantino de que habla en exceso por enfermedad. La melancolía en Huarte permitía hablar, adivinar, incluso profetizar, si bien nunca en colaboración diabólica. La naturaleza y la cultura permiten esos aprendizajes, que son curación. Sancho en la Ilustración será cuentista, poeta, alcalde y modelo de virtudes. Aldea y naturaleza, temperamento y enfermedad hacen al narrador y al poeta. El criado se convierte también en poeta macarrónico, repitiendo rimas. En la llustración se impone el aprendizaje de normas neoclásicas, el Arte poética clásico e ilustrado manda aprender y repetir a los poetas clásicos. Los poetas ya no nacen, se hacen (Gatell, 1794, t. 1, pp. 192-197; Álvarez Barrientos, 1991; Álvarez Barrientos, 2006, pp. 146-155; Carnero, 2009). Pero también Sancho ha aprendido oyendo al amo, como los autores dramáticos. Y como aprendió la virtud y puede convertirse con el sabio Gatell en magnífico alcalde, mejorando enseñanza, artes (teatro, danza, lecturas) y costumbres (Larriba, 2005, pp. 135-149).

En la enseñanza clínica de la época tienen gran importancia dos autores, el escocés William Cullen y el francés Philippe Pinel. Ambos son clínicos hipocráticos, eclécticos, si bien cercanos al vitalismo. La clasificación de Cullen es compleja... asienta la melancolía entre las vesanias. La de Boissier de Sauvages da una hermosa descripción clínica de los tipos de melancolías, que Félix Miquel enseñará en Valencia (Peset, 2013). Por el contrario, la de Pinel coloca en un gran apartado las melancolías, también consideradas vesanias. Estudia este de forma hipocrática casos de manía y melancolía por años en los hospitales de París, pensando en desequilibrios y equilibrios de la naturaleza. Las pasiones desatadas por fuertes sentimientos deben ser compensadas, o bien olvidadas con estímulos contrarios o diversiones. Así, sin llevar la contraria, hay que inducir pensamientos enfrentados que enderecen la mente. Incluso propone fingimientos teatrales, como los que introducirá más tarde el marqués de Sade en Charenton. Intenta, mediante un falso tribunal, sanar a un enfermo que teme la persecución y las penas del Terror revolucionario. Al fin y al cabo no eran más que continuadores de la puesta en escena de matrimonios fingidos para curar el mal de amores que mucho atrás propuso Lope de Vega (Peset, 1993; Peset, 2003; Peset, 2010; Larriba, 2003b).

Aunque algunos de estos autores no pudieron ser leídos por el bachiller Gatell, eran ideas que estaban en la tradición y en la cultura, (Porter, 1992) por lo que no es extraño ver el reflejo en sus escritos. Así, al llegar a la cercanía de la muerte del hidalgo, el cirujano militar Gatell parece resucitar, el médico sustituye al moralista. Al darle con cariño sopa la sobrina, «apenas podía dar sonido a la voz, no tanto por un efecto de la enfermedad, quanto por el pesar que angustiaba su corazón afligido». Nos indica la causa: el loco hidalgo, en sus ataques contra gigantes, caballeros y ejércitos, estaba «dirigido de una imaginación siempre enferma». Como Hipócrates, como Pinel quiere que la naturaleza recupere su curso, contraponiendo a las emociones las contrarias, las opuestas:

Consultóme Sansón, si sería útil contrarrestar vuestras ideas, o bien favorecerlas buscando al mismo tiempo otro medio más poderoso que la persecución, la misma que tiene muy poco poder para convencernos. Persuadidos ambos de esta verdad nos dexábamos llevar muchas veces del mismo torrente que os arrastraba, pero para ocurrir a otros medios. Y en esto ni Sansón ni yo hicimos más de lo que debíamos; bien ciertos por la experiencia antecedente, de que no podrían las razones vencer tan fuerte preocupación.

Al despertar la sobrina llama al clérigo, el caballero reconoce el daño de la imaginación, también la culpa y la expiación:

¡Ha imaginación! iterrible verdugo eres de mi quietud! Todos los trabajos que he pasado en mi vida por mi necedad, no pueden igualarse, Seor Licenciado, con los que he sufrido en este corto rato que he dormido (Gatell, 1792-1793, t. II, pp. 28, 31 y 37-38; Esquirol y Daquin, 2000).

Vuelve, en definitiva, el moralista católico, al decirnos que no escribe para aliviar las penas, es imposible la felicidad humana. El clérigo siempre señala la infelicidad del rico, la presencia continua del dolor y los avisos de la muerte. Aquí de nuevo, cuando Alonso el Bueno despierta, recorre su vida como el cervantino (Quijote, II, c. 74). Arremete contra los libros de caballerías, el fin de la vida es propicio para el arrepentimiento. Si los cincuenta años es la edad del delirio, a ella tan solo una décima parte de la población llega, afirma citando autores de forma erudita:

¡Fuerte desdicha de la humana miseria! la misma fatalidad que se atraxo mi Amigo por haber empleado tan mal aquella mitad del siglo consigue todo hombre que no se ocupa desde su juventud, que sigue solo las sendas de la indolencia, ociosidad y demás vicios (Gatell, 1792-1793, t. I, 156 y 4).

Nos muestra, en fin, la maldad del siglo, en sus jóvenes, en sus mujeres. De aquellos algunos van a América, buscando ricos metales, otros van al contrabando. En definitiva, también a los regimientos, que es mejor salida, servir al rey y a la patria por las armas, ya que no por la agricultura, las artes y las ciencias. La moral ilustrada se une al arbitrismo y reformismo de la época (Hontanilla, 2010; Pérez Martínez, 2012). Prosigue entonces con críticas morales a su tiempo. Aunque fue Alonso Quijano un enfermo de su «dislocada imaginacion», al ingresar en la "caballería imaginaria» - si bien su deseo por Dulcinea, causado por nublado entendimiento, "no sobrepasó los términos de su imaginacion»-, (Gatell, 1792-1793, t. I, pp. 5, 
$8,10,15)$ los Quijotes no perdonaban mujer en el día, doncella, casada o viuda son objeto de su desatada lascivia. Si don Quijote cabalgó en un ardiente julio fue contra agravios, entuertos, sinrazones, abusos y deudas, hoy los caballeros no buscan nada de esto, «pues su deseo no se satisface sino dando rienda á sus vicios.» (Gatell, 1792-1793, t. I, citas en 5-16). En definitiva, lo importante es la moral, parece decirnos.

Hay que rastrear en cientos de páginas de dura doctrina católica de Pedro Gatell los posibles rasgos ilustrados. Tal vez sus cientos de páginas significan la graforrea del melancólico, (Huertas, en prensa; Molinari, 2005) tal vez el signo de los tiempos de contrarrevolución de fines del XVIII. Sin embargo, resultan interesantes sus páginas en cuanto representan críticas y por tanto espejos de costumbres. También en cuanto muestran la evolución del imaginario médico desde humores y melancolías a emociones y pecados. O bien la subjetividad de un olvidado escritor, que grita para ser leído.

\section{BIBLIOGRAFÍA}

Álvarez Barrientos, Joaquín (1991), "La Novela del Siglo XVIII”. En: R. de la Fuente (ed.), Historia de la literatura española 28, Madrid, Gijón, Júcar.

Álvarez Barrientos, Joaquín (2006), Los hombres de letras en la España del siglo XVIII. Apóstoles y arribistas. Madrid, Castalia.

Alsinet, Josef (1794), Nuevo método para curar flatos (...), extractado y traducido por (...). Madrid, Plácido Barco López.

Artigas, Miguel y Sánchez Reyes, Enrique (1957), Catálogos de la Biblioteca de Menéndez Pelayo. I Manuscritos. Santander, Cuerpo facultativo de Archiveros, Bibliotecarios y Arqueólogos, Sociedad Menéndez Pelayo.

Bolufer, Mónica (1998), Mujeres e llustración. La construcción de la feminidad en la España del siglo XVIII. Valencia, Institució Alfons el Magnànim, Diputación de Valencia.

Cadalso, Josep (s.d.), Los eruditos a la violeta. Barcelona, Viuda Piferrer.

Cadalso, Josep (1790), Optica del cortejo. Barcelona, Viudad Piferrer.

Cardano, Gerolamo (1999), El libro de los sueños. Madrid, AEN, trad. Marciano Villanueva Salas.

Carnero, Guillermo (2009), Estudios sobre narrativa y otros temas dieciochescos. Salamanca, Ediciones Universidad de Salamanca, Prensas Universitarias de Zaragoza.

Cullen, Guillermo (1788-1791), Elementos de Medicina Práctica, 4 vols. Madrid, Benito Cano, trad. Bartholomé Piñera.

Diéguez, Antonio (2001), “Mitificación de lo siniestro: sobre La Casa de Locos de Zaragoza", Frenia, vol.1 (1), pp. 129-140.

Discurso sobre el luxô de las señoras, y proyecto de un trage nacional (2005). Madrid, Imprenta Real, 1788. Edición facsímil, Editorial Maxtor, Valladolid.

Egido, Aurora (1994), Cervantes y las puertas del sueño. Estudios sobre La Galatea, El Quijote y El Persiles. Barcelona, PPU, Promociones y Publicaciones Universitarias.
Enciso, Luis Miguel (1956), Nipho y el periodismo español del siglo XVIII. Valladolid, Universidad.

Esquirol, Étienne; Daquin, Joseph (2000), Sobre las pasiones, La filosofía de la locura. Madrid, AEN, trad. María José Pozo, prólogo José Luis Peset.

Fernández Doctor, Asunción (1987), El Hospital Real y General de Nuestra Señora de Gracia de Zaragoza en el siglo XVIII. Zaragoza, Institución Fernando el Católico.

Flores R. M. (1982), Sancho Panza Through Three Hundred Seventyfive Years of Continuations, Imitations, and Criticism, 1605-1980. Newark, Delaware, Juan de la Cuesta - Hispanic Monographs.

Gallego, Antonio (1988), La música en tiempos de Carlos III. Alianza Editorial, Madrid.

García Asensio, Miguel (1785), "El Lacayo Marques Fin de Fiesta", Biblioteca Marcelino Menéndez Pelayo. Santander, Manuscritos, sig. M 42, pp. 70r-123v.

Gatell, Pedro (1792-1793), La moral de don Quijote, deducida de la historia que de sus gloriosas hazañas escribió Cide-Hamete Benengelí. Por su grande amigo el cura. Dala á luz el Br. D. P. Gatell, 2 vols. Madrid, Imprenta de González.

Gatell, Pedro (1794), Historia del mas famoso escudero Sancho Panza, despues de la muerte de Don Quixote de la Mancha, t. I. Madrid, Imprenta Real.

Gatell, Pedro (1912), "Memoria en la que se demuestra la absoluta necesidad en que se halla la corte de España de poblar y fortificar la Luisiana..." (Año 11 octubre 1780). En: Documentos históricos de la Florida y la Luisiana siglos XVI al XVIII, Madrid, Librería General de Victoriano Suárez, pp. 353-360.

Gatell, Pedro (2010), Cide Hamet Benengell, La moral del mas famoso escudero Sancho Panza. Madrid, Imprenta Real, 1793, facsimilar Extramuros Edición, Mairena del Aljarafe, Sevilla.

Gusdorf, Georges (1976), Naissance de la conscience romantique au siècle des Lumières. Paris, Payot. 
Gutiérrez Cuadrado, Juan (2005), “Arcaísmos y otros '-ismos': la selección léxica en el Quijote", Boletín de la Real Academia Española, LXXXV, pp. 335-374.

Hervás y Panduro, Lorenzo (1807), Causas de la revolucion de Francia en el año de 1789, 2 vols. Madrid, s.i.

Hoffmann, Paul (1995), La femme dans la pensée des Lumières. Gèneve, Slatkine Reprints.

Hontanilla, Ana (2010), El gusto de la razón. Debates de arte y moral en el siglo XVIII español. Madrid, Frankfurt am Main, Iberoamericana, Vervuert Verlag.

Huertas, Rafael (en prensa), "'You will have observed that I am not mad'. Emotional Writings inside the Mental Asylum".

Larriba, Elisabel (ed. e int.) (2003a), El Argonauta español. Periódico gaditano por el bachiller D. P. Gatell. Cádiz, Servicio de Publicaciones de la Universidad de Cádiz.

Larriba, Elisabel (2003b), "El matrimonio en la obra del bachiller Pedro Gatell y Carnicer (1745-1792)”. En: Roberto Fernández y Jacques Soubeyroux (Eds.), Historia social y literatura. Familia y burguesía en España (siglos XVIII y XIX), Lleida, Barcelona, Editorial Milenio.

Larriba, Elisabel (2005), De la lancette à la plume: Pedro Pablo Gatell y Carnicer. Un chirurgien de la Marine Royale dans l'Espagne des Lumières. Aix-en Provence, Publications de I'Université de Provence.

Lolo, Begoña (Comisaria) (2003), Paisajes sonoros en el Madrid del siglo XVIII. La tonadilla escénica. Madrid, Museo de San Isidro, Ayuntamiento de Madrid.

Méndez, Cristóbal (1991), Libro del ejercicio corporal, y de sus prouechos, por el qual cada vno podra entender que exercicio le sea necessario para conservar su salud, Jaén, s.i., 1553. Edición Academia Nacional de Medicina, México, estudio y edición Juan Somolinos Palencia, Rafael Zárate Cueto y Esperanza Medina Navascuez.

Molinari, Augusta (2005), "Autobiografías de mujeres en un manicomio italiano a principios del siglo XX". En: Antonio Castillo y Verónica Sierra (Eds.), Letras bajo sospecha, Gijón, Trea, 379-400.

Montiel, Luis (2008), Magnetizadores y sonámbulas en la Alemania romántica. Madrid, Frenia.

Montiel, Luis y González de Pablo, Ángel (Coords), (2003), En ningún lugar en parte alguna. Estudios sobre la historia del magnetismo animal y del hipnotismo. Madrid, Frenia.
Muratori, Luis Antonio (1777), Fuerza de la humana fantasía. Madrid, Imprenta de D. Manuel Martín, trad. Br. Vicente Mạ. de Tercilla.

Nipho, Francisco Mariano (1755), Representacion (de burlas hecha de veras) al nobilissimo gremio de los hombres de juicio de esta gloriosa Monarquia, en la que manifiesta la España antigua sus honrados sentimientos contra los perniciosos, y detestables abusos de la España moderna. Madrid, Oficina de Joseph de Orga.

Pérez García, Norberto (2006), "Una continuación dieciochesca del Quijote: la Historia del más famoso escudero Sancho Panza", Anales cervantinos, 38, pp. 247-257.

Pérez Martínez, A. (2012), El Quijote y su idea de virtud. Madrid, CSIC.

Peset, José Luis (1988), “Malaspina, el héroe necesario (a modo de prólogo)". En: Andrés Galera, La llustración española y el conocimiento del Nuevo Mundo, Madrid, CSIC, pp. ix-xviii.

Peset, José Luis (1993), Las heridas de la ciencia. Valladolid, Junta de Castilla y León.

Peset, José Luis (1999), Genio y desorden. Valladolid, Cuatro Ediciones.

Peset, José Luis (2003): "Philippe Pinel's Hippocratic Revolution". En: F. Fuentenebro, R. Huertas y C. Valiente (Eds.), Historia de la Psiquiatría en Europa. Temas y tendencias, Madrid: Frenia, S. C., pp. 93-106.

Peset, José Luis (2010), Las melancolías de Sancho. Humores y pasiones entre Huarte y Pinel. Madrid, AEN.

Peset, José Luis (2013), “La melancolía y los médicos: humores y pasiones en la Ilustración española" En: Gloria Clavería et al (eds.), Historia, lengua y ciencia: una red de relaciones, Frankfurt am Main, Peter Lang Edition, pp. 217-236.

Pi y Molist, Emilio (1886), Primores del don Quijote. Barcelona, Imprenta Barcelonesa.

Porter, Roy (Ed.) (1992), The Popularization of Medicine 1650-1850. London and New York, Routledge.

Ruiz Somavilla, Mạ. José (1993), "El cuerpo limpio". Análisis de las prácticas higiénicas en la España del mundo moderno. Málaga, Universidad de Málaga.

Staël, Madame de (2007), De la influencia de las pasiones en la felicidad de los individuos y de las naciones. Reflexiones sobre el suicidio. Córdoba, Berenice, edición, introducción y traducción de David Marín Hernández. 